\title{
Condensed tannins from Ficus altissima leaves: Structural, antioxidant, and antityrosinase properties
}

\author{
Yi-Tao Deng ${ }^{\mathrm{a}, \#}$, Ge Liang ${ }^{\mathrm{a}, \#}$, Yan Shi ${ }^{\mathrm{a}}$, Hua-Liang Li ${ }^{\mathrm{a}}$, Jing Zhang ${ }^{\mathrm{a}}$, Xiao-Mei Mao ${ }^{\mathrm{a}}$, \\ Qi-Rui Fu' ${ }^{\mathrm{a}}$, Wei-Xi Peng ${ }^{\mathrm{a}}$, Qing-Xi Chen ${ }^{\mathrm{a}}$, and Dong-Yan Shen ${ }^{\mathrm{b}}$
}

${ }^{a}$ State Key Laboratory of Cellular Stress Biology, Key Laboratory of the Ministry of Education for Coastal and Wetland Ecosystems, School of Life Sciences, Xiamen University, Xiamen 361005, People's Republic of China

${ }^{\mathrm{b}}$ Center Laboratory, the First Affiliated Hospital of Xiamen University, Xiamen 361003, People's Republic of China

\# Yi-Tao Deng and Ge Liang contributed equally to this study.

Corresponding authors:

Dr Qing-Xi Chen

State Key Laboratory of Cellular Stress Biology

Key Laboratory of the Ministry of Education for Coastal and Wetland Ecosystems

School of Life Sciences

Xiamen University

Xiamen 361005

People's Republic of China

E-mail: chenqx@xmu.edu.cn

Dr Dong-Yan Shen 
Center Laboratory

The First Affiliated Hospital of Xiamen University

Xiamen 361003

People's Republic of China

E-mail: shendongyan@163.com 


\section{Abstract}

The total phenolic content and the concentration of extractable and bound condensed tannins of Ficus altissima leaves were determined. The antioxidant activity of crude extracts and condensed tannins of $F$. altissima leaves was evaluated using 2,2-diphenyl-1-pichydrazyl (DPPH), 2,2-azino-bis-(3-ethylbenzothiazoline-6-sulfonic acid) (ABTS), and ferric-reducing antioxidant power (FRAP) methods. The results showed that condensed tannins possessed higher free radical scavenging power. The structure of condensed tannins was characterized using high-performance liquid chromatography electrospray ionization mass spectrometry coupled with thiolysis and matrix-assisted laser desorption/ionization time-of-flight mass spectrometry. The findings showed that condensed tannins from $F$. altissima leaves were mixtures of procyanidins, prodelphinidins, and propelargonidins with a degree of polymerization up to 30-mer. In addition, condensed tannins effectively protected plasmid DNA against free radical damage and alleviated $t$-butylhydroperoxide-induced cytotoxicity on human hepatocyte LO2 cells. Condensed tannins exhibited remarkable inhibitory effects on both monophenolase and diphenolase activities of tyrosinase. The $\mathrm{IC}_{50}$ values were estimated to be $256.7 \pm 0.3$ and $41.3 \pm 0.2 \mu \mathrm{g} / \mathrm{mL}$, respectively. For the diphenolase activity, inhibition by condensed tannins was reversible and of mixed-type. Condensed tannins from leaves of $F$. altissima were indicated to possess significant antioxidant and antityrosinase activities, suggesting that $F$. altissima might be a good source of proanthocyanidins with biological activity.

Keywords: condensed tannins; Ficus altissima; antioxidant; antityrosinase; structural characterization 


\section{Introduction}

Tyrosinase (EC 1.14.18.1), or polyphenoloxidase (PPO), ${ }^{1}$ is a copper-containing enzyme widely found in microorganisms, plants, and animals. ${ }^{2}$ It catalyzes two consecutive reactions in the conversion of tyrosine to melanin, hydroxylation of monophenols (tyrosine) to diphenols (dihydroxyphenylalanine (DOPA)) by monophenolase activity, and oxidation of diphenols (DOPA) to diquinones (DOPA quinone) by diphenolase activity. ${ }^{1,3}$ Tyrosinase-catalyzed browning in vegetables and fruits leads to less attractive appearance and loss in nutritional quality. ${ }^{4}$ Overproduction of melanin may result in a large number of skin maladies, including age spots, melasma, postinflammatory melanoderma, solar lentigo, freckles, and chloasma. ${ }^{1,5,6}$ Therefore, tyrosinase inhibitors have attracted much interest in food, dermatological, and cosmetic industries. Despite the large number of tyrosinase inhibitors identified from natural or synthetic sources, their side effects restrict their application for commercial purposes. ${ }^{3}$ Hence, it is worth exploring effective natural tyrosinase inhibitors from plant resources. It is reported that condensed tannins derived from plants exhibited potent tyrosinase inhibitory activity. ${ }^{7,8}$

Condensed tannins, the so-called proanthocyanidins (PAs), ${ }^{9}$ are complex polymers of favan-3-ol units that naturally occur in cereals, legume seeds, fruits, and beverages. ${ }^{10}$ The flavan-3-ol units possess typical C6-C3-C6 flavonoid skeleton. The condensed tannins are diverse in structure and molecular mass with variation of flavonoid monomers, interflavonoid linkage position, and modifications with nonflavonoid substituents. ${ }^{11}$ Condensed tannins in food include procyanidins (PCs), prodelphinidins (PDs), and propelargonidins (PPs), with subunits of catechin/epicatechin, gallocatechin/epigallocatechin, and afzelechin/epiafzelechin, respectively (Fig. 1). ${ }^{10}$ These polymeric compounds are found to possess antioxidant, ${ }^{7,12}$ antifungal, $^{13}$ 
antienzymatic, ${ }^{7,12,14}$ and antitumor activities. ${ }^{15}$

Ficus, namely the fig genus, is composed of $>800$ species and is one pantropical genus of Moraceae, the mulberry family. ${ }^{16,17}$ The tiny flowers are massed on the inside wall and invisible from outside, and hence figs are referred to as "no flower fruit" in Chinese medicine. ${ }^{16}$ As a large number of animals in tropical forests feed on their fruits (syconia), ${ }^{17-19}$ figs are regarded as keystone resources in tropical forests $^{19,20}$ and considered to be ecologically significant. ${ }^{17,18}$ Structures $^{14,21}$ and biological activities ${ }^{14,21-23}$ of condensed tannins from various Ficus species have been investigated in the literature. So far, however, Ficus altissima has been rarely researched on the development of condensed tannins. F. altissima (Ficus), a monoecious tree, ${ }^{17,19}$ is widely distributed across Asia. ${ }^{17,24}$ It occurs naturally in tropical forests and is also largely planted in cities to renovate the urban landscape. ${ }^{20}$ Hence, F. altissima could be a potential resource of condensed tannins. The objective of this study was to determine the total phenol and extractable and bound condensed tannins content of $F$. altissima leaves, and to investigate the structure and antioxidant and antityrosinase properties of condensed tannins to provide effective scientific data for comprehensive utilization of $F$. altissima in the fields of food, cosmetics, and medicine.

\section{Materials and methods}

\subsection{Chemicals}

Mushroom tyrosinase, L-tyrosine, 3,4-dihydroxyphenylalanine (L-DOPA), 2,2-diphenyl-1-pichydrazyl (DPPH), 2,2-azino-bis-(3-ethylbenzothiazoline-6-sulfonic acid) (ABTS), 2,4,6-tripyridyl-striazine (TPTZ), Sephadex LH-20, trifluoroacetic acid (TFA), benzyl mercaptan, dimethyl sulfoxide-d6 (DMSO-d6), and ascorbic acid were purchased from Sigma-Aldrich (St Louis, Missouri, USA). 
3-(4,5-Dimethylthiazol-2-yl)-2,5-diphenyl tetrazolium bromide (MTT) and sodium dodecyl sulfate (SDS) were purchased from Sangon Biotech (Shanghai, China). Dulbecco's modified Eagle's medium (DMEM) and fetal bovine sera were purchased from Gibco (Grand Island, NY, USA). GoldView was purchased from Solarbio (Beijing, China). All the other solvents and reagents were obtained from Sinopharm (Shanghai, China).

\subsection{Preparation of condensed tannins from F. altissima leaves}

Leaves of F. altissima were collected in October 2015 from the campus of Xiamen University (Xiamen, China). They were washed with $\mathrm{ddH}_{2} \mathrm{O}$ and lyophilized immediately, and ground to fine powders. Each $10 \mathrm{~g}$ of powder sample was ultrasonically extracted thrice with $100 \mathrm{~mL}$ of acetone-water solution $(7: 3, \mathrm{v} / \mathrm{v})$ at room temperature. Acetone was eliminated with rotary evaporation at $40^{\circ} \mathrm{C}$. Then, each $100 \mathrm{~mL}$ of the aqueous fraction was extracted thrice with $33.3 \mathrm{~mL}$ of petroleum ether to remove chlorophyll and lipophilic compounds. The aqueous fraction was lyophilized and stored as crude extracts in $-20^{\circ} \mathrm{C}$ The crude extracts were purified by chromatography according to the method of Chai et al. ${ }^{7}$

\subsection{Determination of total phenol content}

The total phenol content was determined using the method of Folin-Ciocalteu ${ }^{25}$ and expressed as milligrams of GA equivalents per gram dry weight of extract (mg GAE/g DW).

2.4. Determination of extractable, protein- and fiber-bound condensed tannins

Extractable and bound condensed tannins were determined based on the procedure of Barry et al. with modification. ${ }^{26}$ The solutions were centrifuged at $12,000 \mathrm{~g}$. Standards were prepared from 1-g/L stock solutions of $F$. altissima leaf-condensed tannins both in water and SDS solution, which were used to analyze extractable and 
bound condensed tannins, respectively.

2.5. DPPH radical scavenging activity assay

The DPPH radical scavenging activity of samples was determined as described in ref.

2.6. ABTS radical scavenging activity assay

The ABTS assay was performed as described in ref. [27]. Ascorbic acid was used as an antioxidant standard.

2.7. Ferric-reducing antioxidant power assay

The FRAP assay was carried out as described in ref. [7]. Ascorbic acid was tested as a standard, and FRAP values were expressed as milligrams of ascorbic acid equivalents (AAEs) per gram of sample by a standard curve.

2.8. Thiolysis of condensed tannins with benzyl mercaptan

Condensed tannins were subjected to thiolysis with benzyl mercaptan according to the process descried in ref. [7].

\subsection{RP-HPLC-ESI-MS analysis}

The reversed-phase high-performance liquid chromatography electrospray ionization mass spectrometry (RP-HPLC-ESI-MS) analysis was performed according to the procedure of Chai et al. ${ }^{7}$

2.10. MALDI-TOF-MS analysis

The matrix-assisted laser desorption/ionization time-of-flight mass spectrometry (MALDI-TOF-MS) analysis was performed on an AB SCIEX TOF/TOFTM 5800 MALDI-TOF mass spectrometer (AB SCIEX, USA). The parameters for positive-mode spectra in the reflectron and linear modes were set according to the previous study. $^{7}$

2.11. Protective effect of condensed tannins against DNA damage induced by 
hydroxyl free radicals

The protective activity was tested as according to the study by Kim et al. with modification. ${ }^{28}$ The pLV DNA was subjected to oxidation, and DNA bands stained with GoldView were observed under an ultraviolet (UV) transmission analyzer.

\subsection{Cell culture}

Human hepatocyte LO2 cells were cultured in DMEM according to the procedure described by Fu et al. ${ }^{29}$ The culture medium was renewed every $24 \mathrm{~h}$, and cells were passaged every 2 days. The cells were cultured for 20 days at most, and new lines were revived from frozen stocks.

\subsection{Cytotoxicity analysis}

Cell viability was determined by the MTT method described previously with some modifications. ${ }^{30}$ Condensed tannins were dissolved in PBS (pH 7.2) and PBS was used as control. After 12-h incubation, the cells were treated with condensed tannins at various concentrations. MTT $(5 \mathrm{mg} / \mathrm{mL}, 20 \mu \mathrm{L})$ solution was added to each well after $10-\mathrm{h}$ treatment. The cells were incubated for $4 \mathrm{~h}$. Then, the supernatant was removed and $150 \mu \mathrm{L}$ of DMSO was added to each well. The absorbance of the solution was recorded at $570 \mathrm{~nm}$. The cytotoxic effect was calculated as follows: cell viability $\%=A_{1} / A_{0} \times 100$, where $A_{1}$ is the absorbance of the condensed tannins group, and $\mathrm{A}_{0}$ is the absorbance of the control group.

2.14. Protective activity of condensed tannins against $t$-BHP-induced damage in human hepatocyte LO2 cells

Human hepatocyte $\mathrm{LO} 2$ cells were treated with different concentrations of condensed tannins for $10 \mathrm{~h}$, and then incubated in DMEM containing $200 \mu \mathrm{M}$ of $t$-BHP for $2 \mathrm{~h}$. The supernatant was removed and the new DMEM was added. Cell viability was measured using the MTT method. ${ }^{28}$ 


\subsection{Tyrosinase inhibitory assay}

Tyrosinase activity was determined according to the procedure reported in ref. [31]. The samples were dissolved in $\mathrm{ddH}_{2} \mathrm{O}$ and diluted to suitable concentrations. The inhibition type was assayed by analyzing the Lineweaver-Burk plot.

\subsection{Fluorescence quenching}

The experiment was carried out according to the protocol described in ref. [12]. The fluorescence spectra were recorded using a Cary Eclipse fluorescence spectrophotometer. The fluorescence emission spectra were detected at a position of $300-500 \mathrm{~nm}$ upon excitation at $290 \mathrm{~nm}$.

\subsection{Statistical analysis}

Data were expressed as mean \pm standard deviation (SD) of three replicated determinations. Comparisons between results were analyzed by one-way analysis of variance (ANOVA). Differences were regarded as significant at $p<0.05$.

\section{Results and discussion}

3.1. Total phenols, extractable and protein- and fiber-bound condensed tannins contents in leaves of $F$. altissima

The total phenolic contents of crude extracts and condensed tannins from $F$. altissima leaves were determined to be $431.9 \pm 12.0$ and $527.1 \pm 6.4 \mathrm{mg}$ GAE/g DW, respectively, and the total phenolic content of leaves was calculated to be $118.4 \pm 3.3$ mg GAE/g DW, which was considerably higher than that of some other Ficus species. ${ }^{32}$ In addition, the extractable and protein- and fiber-bound condensed tannins contents in leaves of $F$. altissima were measured to be $39.61 \pm 1.02,1.19 \pm 0.11$, and $0.42 \pm 0.01 \mathrm{mg} / \mathrm{g}$ DW, respectively, and the total condensed tannins concentration was calculated to be $41.22 \pm 1.07 \mathrm{mg} / \mathrm{g}$ DW. The results indicated that extractable condensed tannins were the major groups, comprising approximately $96.1 \%$ of the 
condensed tannins in $F$. altissima leaves.

\subsection{Antioxidant activities}

It is very important to scavenge free radicals as they are toxic in foods and biological systems. ${ }^{33}$ It is necessary to multilaterally study the antioxidant capacity of a biological material by different types of assays. ${ }^{34,35}$ In this study, three different methods were used to compare the antioxidant activity of crude extracts and condensed tannins. The DPPH method has been widely used to evaluate the free radical scavenging capacity of natural products. ${ }^{36-38}$ DPPH is a stable and commercially available radical. When mixed with a reducing agent, DPPH would be scavenged with a decrease of absorbance of the solution at $517 \mathrm{~nm}$. The antioxidant activity of a sample could be assessed according to the loss of absorbance. DPPH could only be dissolved in organic systems; however, ABTS can be dissolved in aqueous and organic media. Therefore, ABTS can be used to examine the antioxidant activity of hydrophilic and lipophilic compounds. ABTS radical is more reactive than DPPH radical. Reactions with DPPH radical involve $\mathrm{H}$ atom transfer, while those with ABTS radical involve an electron transfer process. ${ }^{33}$ FRAP is also a simple assay measuring total antioxidant power, while the reaction is carried out in acidic condition. When a ferric radical is reduced to the ferrous form, an optical density of the solution at $593 \mathrm{~nm}$ increases intensely. ${ }^{39}$

As shown in Figure 2A, crude extracts and condensed tannins scavenged DPPH radicals in a dose-dependent manner. The $\mathrm{IC}_{50}$ values of ascorbic acid, crude extracts, and condensed tannins for DPPH radical scavenging activity were 79.26 $\pm 0.52,94.25$ \pm 0.60 , and $61.19 \pm 0.44 \mu \mathrm{g} / \mathrm{mL}$, respectively. A lower $\mathrm{IC}_{50}$ value represents a higher antioxidant effect. F. altissima leaf-condensed tannins exhibited approximately 1.30 times DPPH free radical scavenging capacity of ascorbic acid. In the assay of ABTS, 
the $\mathrm{IC}_{50}$ values of ascorbic acid, crude extracts, and condensed tannins were determined as $83.56 \pm 0.40,137.13 \pm 5.68$, and $91.32 \pm 0.84 \mu \mathrm{g} / \mathrm{mL}$, respectively (Fig. 2B). The results of FRAP assay are shown in Figure 2C; the FRAP values of crude extracts and condensed tannins are found to be $885.48 \pm 8.28$ and $1002.40 \pm 7.72 \mathrm{mg}$ AAE/g, respectively.

The results of all the above assays showed that condensed tannins together with a higher phenolic content possessed more potent free radical scavenging capacity than crude extracts, which compared favorably to the previous studies of Ficus species leaf. $^{32}$ Nevertheless, the antioxidant activity of crude extracts from $F$. altissima leaves was better than those of several extracts in the previous studies. ${ }^{40,41}$

\subsection{RP-HPLC-EPI-MS coupled with benzyl mercaptan thiolysis}

Thiolysis with benzyl mercaptan combined with RP-HPLC-ESI-MS analysis is an effective method to identify the constituent flavonoid units in condensed tannins. ${ }^{7,12}$ The chromatogram of degradation products of condensed tannins from leaves is shown in Figure 3. The extension units contained catechin/epicatechin, gallocatechin/epigallocatechin, and afzelechin/epiafzelechin, and the terminal units were only catechin and epicatechin. In addition, the mean degree of polymerization (mDP) of condensed tannins was calculated to be 6.9 using a method described in James et al. $^{42}$

\subsection{MALDI-TOF-MS analysis}

It is viable to analyze complex structural characteristics of condensed tannins in foods such as hydroxylation pattern in the $\mathrm{B}$ ring, substituent groups in the $\mathrm{C}$ ring, and degree of polymerization by MALDI-TOF-MS technique. ${ }^{43}$ MALDI-TOF positive ion $\left(\mathrm{Cs}^{+}\right)$mass spectra of condensed tannins in the reflectron and linear modes are shown in Figure 4. In the reflectron-mode spectrum (Fig. 4A), a series of periodically 
repeating peak groups revealed the polydispersity of condensed tannins from $F$. altissima leaves. The highest peaks of the periodic peak groups increased equally from 1287 (4-mer) to $4743 \mathrm{Da}$ (16-mer) at a distance of $288 \mathrm{Da}$, with the addition of one (epi)catechin monomer unit. Peaks with mass lower or higher than $16 \mathrm{Da}$ were detected near a few homopolyflavan-3-ol peaks, indicating that one monomer unit of these polymers contained one or three hydroxyl groups (16 Da) in the B-ring (Fig. 4A). The results revealed the existence of (epi)afzelechin and (epi)gallocatechin monomer units. Furthermore, each main peak was followed by mass signals at a distance of $162 \mathrm{Da}$, and a few highest peaks followed by mass signals at a distance of 152 or $132 \mathrm{Da}$. The 162-Da mass distance was in accordance with the addition of one glucose group at the heterocyclic C-ring. ${ }^{14}$ The 152-Da mass distance agreed with the addition of one galloyl group in the C-ring. The 132-Da mass distance can be attributed to the substitution of a pentoside or synchronous attachment of two cesium ions to the polymers. ${ }^{43}$ In addition, the linear MALDI-TOF mass spectrum is shown in Figure 4B, showing the degree of polymerization up to 30-mer.

To conclude, the results of RP-HPLC-ESI-MS and MALDI-TOF-MS analyses indicated that condensed tannins from the leaves of $F$. altissima were dominated by PCs, containing a small number of PDs and very few PPs. Polyphenols scavenge free radicals, such as singlet oxygen and alkyl peroxyl radicals, by donating an electron and generating a relatively stable phenoxyl radical. For most PAs, the radical site is at the B-ring. ${ }^{10}$ PCs have better antioxidant ability than PPs, ${ }^{7}$ and gallocatechins with a 3',4',5'-trihydroxyphenyl B-ring possess a higher scavenging power than catechins. Galloylation is also able to enhance the scavenging ability. The effect of polymerization degree is ambiguous. ${ }^{10}$ Hence, the potent radical scavenging capacity of condensed tannins from $F$. altissima leaves could be attributed to their high 
proportion of PCs and the existence of a certain amount of galloylation. The results were in good accordance with the investigation of the free radical scavenging capacity of grape seed extracts and Pycnogenol. ${ }^{44}$

\subsection{Inhibitory activity of condensed tannins on hydroxyl-induced DNA damage}

When exposed to hydroxyl radicals, supercoiled (SC) plasmid DNA would be cleaved into two forms: open circular (OC) and linear. ${ }^{28,45}$ The protective effect of condensed tannins on plasmid DNA is shown in Figure 5. Plasmid DNA was dominated by SC form, containing a small amount of OC and linear forms (line 1). When mixed with reaction agents, the SC form was completely broken into the linear form (line 2). However, when treated with reaction mixture and condensed tannins at different concentrations simultaneously, only a part of SC DNA was converted to linear form (line 3-6). As shown in Figure 5, the condensed tannins $(6.25,12.5,25$, and $50 \mu \mathrm{g} / \mathrm{mL})$ protected plasmid DNA against hydroxyl radical in a dose-dependent manner.

Highly reactive oxygen species regularly produced in human body participate in pathogenesis and aging through causing damage to lipids, proteins, and DNA. The consumption of dietary polyphenols and other natural antioxidants such as vitamins $\mathrm{C}$ and $\mathrm{E}$ can prevent the damage. ${ }^{10}$ In the Fenton reaction, iron plays a catalytic role in the generation of hydroxyl radical $(\mathrm{OH} .)^{44}$ In this study, condensed tannins effectively inhibited the hydroxyl radical-induced DNA damage. According to the previous reports, the plasmid might be protected by condensed tannins through chelation of transition metals ${ }^{46}$ and electron or hydrogen-atom transfer. ${ }^{45}$

\subsection{Inhibitory activity of condensed tannins on $t$-BHP in LO2 cells}

Human nontumor hepatic cell line LO2 was used to test the protective effect of condensed tannins against $t$-BHP-induced damage. The effect of condensed tannins on viability of LO2 cell was determined initially as viability 1 (Table 1). The results 
showed that condensed tannins at tested concentrations obviously stimulated the proliferation of LO2 cell within a short time $(10 \mathrm{~h})$. After being exposed to condensed tannins for $10 \mathrm{~h}$ and $t$-BHP for $2 \mathrm{~h}$ successively, cell viability of LO2 denoted by viability 2 increased remarkably with increasing concentrations of condensed tannins (Table 1). In view of the growth simulation effect of condensed tannins, the protective effect of condensed tannins was calculated as the value of viability 2 divided by viability 1 , denoted by viability 3 . As shown in Table 1 , viability 3 also increased significantly at tested concentrations, showing that condensed tannins efficiently inhibited the cytotoxicity of $t$-BHP on LO2 cells.

Derived from primary normal human hepatocyte, the LO2 cell line maintains the biological features and ultrastructures of normal adult hepatocytes. ${ }^{47}$ As a well-known organic hydroperoxide, $t$-BHP can rapidly penetrate mammalian cells. ${ }^{28}$ Overproduction of ROS can poison and ultimately kill cells. Despite possessing nonenzymatic and enzymatic defensive mechanisms to prevent ROS formation or detoxify ROS, mammalian cells cannot completely avoid the damage from ROS. Hence, antioxidants that can enhance the cellular defense are proposed to be the therapeutic agents to manage excessive formation of ROS. Kim et al. reported that the oligomeric and polymeric PC fractions from grape seeds exerted significant cytoprotective effects in HepG2 cells against $t$-BHP-induced oxidative damage through modulating ROS production, glutathione levels, malondialdehyde generation, and antioxidant enzyme activities. ${ }^{48}$ The condensed tannins in this study were composed mainly of PCs, implying that condensed tannins from $F$. altissima leaves might effectively protect the LO2 cells from $t$-BHP-dependent injury by mechanisms similar to the PC fractions from grape seeds.

3.7. Inhibitory effect on the monophenolase activity of mushroom tyrosinase 
Condensed tannins were tested for their effect on the activity of mushroom tyrosinase for oxidation of ${ }_{L}$-Tyr. As shown in Figure 6A, with increasing concentrations, the steady-state rate decreased remarkably, while the lag time did not change. The concentration leading to $50 \%$ loss of enzyme activity $\left(\mathrm{IC}_{50}\right)$ was determined to be $256.7 \pm 0.3 \mu \mathrm{g} / \mathrm{mL}$. The monophenolase inhibitory activity was much higher than the methanol extracts of Magnolia denudata and M. denudata var. purpurascens flowers in the previous report, whose $\mathrm{IC}_{50}$ values were 3343.58 and $10,555.55 \mu \mathrm{g} / \mathrm{mL}$, respectively. ${ }^{49}$

\subsection{Inhibitory effect on the diphenolase activity}

As shown in Figure 6B, the diphenolase activity decreased distinctly in a dose-dependent manner. The value of $\mathrm{IC}_{50}$ was estimated to be $41.3 \pm 0.2 \mu \mathrm{g} / \mathrm{mL}$. Chung-Yi Wang et al. discovered that methanol extracts of sorghum distillery residue exhibited tyrosinase-inhibiting activity with an $\mathrm{IC}_{50}$ of $580 \mu \mathrm{g} / \mathrm{mL}{ }^{50}$ Compared with the previous studies cited above, condensed tannins in our study were potent tyrosinase inhibitors.

\subsection{Inhibition mechanism on the diphenolase activity}

Figure $6 \mathrm{~B}$ shows that in the plot of the remaining diphenolase activity against the concentration of enzyme at various concentrations of condensed tannins, different sets of dots formed a group of straight lines passing through the origin. The slopes of these lines decreased with the increasing dose of the inhibitor, indicating that the addition of the effector caused the inhibition of enzyme activity without the loss of enzyme quantity. The inhibition was reversible.

\subsection{Inhibition type on the diphenolase activity}

As shown in Figure 6C, Lineweaver-Burk plots produced a series of lines intersecting at the second quadrant, indicating that condensed tannins were mixed-type inhibitors, 
and the inhibition constants $\left(K_{I}\right.$ and $\left.K_{I S}\right)$ were estimated to be 49.25 and $33.79 \mu \mathrm{g} / \mathrm{mL}$, respectively.

\subsection{Analysis of fluorescence quenching of tyrosinase with condensed tannins}

Because tryptophan fluorescence takes place among the intrinsic aromatic fluorophores in tyrosinase, fluorescence quenching analysis has been frequently performed to obtain information about conformational changes. ${ }^{12,51}$ The interaction of tyrosinase with condensed tannins and the changes of tyrosinase conformation were evaluated by measuring the intrinsic fluorescence intensity of the enzyme in the absence and presence of samples at different concentrations. Tyrosinase shows a strong fluorescence emission peak at $337 \mathrm{~nm}$ upon excitation at $290 \mathrm{~nm}$. Figure 6D shows that condensed tannins exhibit a fluorescence emission peak at $316 \mathrm{~nm}$ (curve A). Condensed tannins decreased dramatically the fluorescence emission intensity of tyrosinase with an increasing concentration. The fluorescence intensity was reduced from 49.7 to 25.3 (by $49 \%$ ) as the concentration of condensed tannins increased from 0 to $20 \mu \mathrm{g} / \mathrm{mL}$. Decline in the fluorescence intensity without a significant shift of emission peak indicated that the enzyme bound to condensed tannins solely depends on the concentration. ${ }^{51}$ In the study of Chai et al., an obvious blue shift occurred when tyrosinase was associated with PAs from fruit stone of Chinese hawthorn, indicating that the enzyme conformation was changed. Moreover, PAs had been reported to chelate $\mathrm{Cu}^{2+}$. The combination of hydroxyl group of PAs and copper ions in the catalytic center of tyrosinase might be responsible for the inhibitory capacity of PAs on tyrosinase. ${ }^{12}$

\section{Conclusions}

In this study, the total phenol and condensed tannin contents of $F$. altissima leaves were measured to be $118.4 \pm 3.3 \mathrm{mg} \mathrm{GAE} / \mathrm{g}$ DW and $41.22 \pm 1.07 \mathrm{mg} / \mathrm{g} \mathrm{DW}$, 
respectively. Except for their potent DPPH and ABTS scavenging capacity and ferric-reducing antioxidant power (FRAP), condensed tannins of leaves from $F$. altissima were able to effectively protect plasmid DNA against hydroxyl radicals and prevent cellular damage caused by organic hydroperoxide $t$-BHP. The structure of condensed tannins was elucidated by RP-HPLC-ESI-MS and MALDI-TOF-MS for the first time. The results showed that condensed tannins were dominated by PCs, containing a small quantity of PDs and very few PPs, and the degree of polymerization was determined up to 30 -mer. The remarkable antioxidant activity could be mainly attributed to the abundant ortho-dihydroxyl structure of the B-ring. Furthermore, condensed tannins exhibited a high inhibitory effect on monophenolase activity as well as diphenolase activity of tyrosinase. Our findings suggest that $F$. altissima might be a potential new source of PAs with biological activities.

\section{Acknowledgments}

This study was supported by the Natural Science Foundation of China (Grant No. 31571896) and the National Science Foundation for Fostering Talents in Basic Research of the National Natural Science Foundation of China (Grant No. J1310027).

\section{References}

[1] YS Baek, YB Ryu, MJ Curtis-Long, TJ Ha, R Rengasamy, MS Yang, KH Park, Tyrosinase inhibitory effects of 1,3-diphenylpropanes from Broussonetia kazinoki, Bioorganic \& Medicinal Chemistry 17 (2009) 35-41.

[2] JC Espin, PA Garcia-Ruiz, J Tudela, F Garcia-Canovas, Study of stereospecificity in mushroom tyrosinase, Biochemical Journal 331 (1998) 547-551.

[3] A Husni, JS Jeon, BH Um, NS Han, D Chung, Tyrosinase inhibition by water and ethanol extracts of a Far Eastern sea cucumber, Stichopus japonicus, Journal of the Science of Food and Agriculture 91 (2011) 1541-1547.

[4] L Qiu, QH Chen, JX Zhuang, X Zhong, JJ Zhou, YJ Guo, QX Chen, Inhibitory effects of alpha-cyano-4-hydroxycinnamic acid on the activity of mushroom tyrosinase, Food Chemistry 112 (2009) 609-613.

[5] S Briganti, E Camera, M Picardo, Chemical and instrumental approaches to treat hyperpigmentation, Pigment Cell Research 16 (2003) 101-110.

[6] CK Hsu, CT Chang, HY Lu, YC Chung, Inhibitory effects of the water extracts of Lavendula sp on 
mushroom tyrosinase activity, Food Chemistry 105 (2007) 1099-1105.

[7] WM Chai, Y Shi, HL Feng, L Qiu, HC Zhou, ZW Deng, CL Yan, QX Chen, NMR, HPLC-ESI-MS, and MALDI-TOF MS Analysis of Condensed Tannins from Delonix regia (Bojer ex Hook.) Rat and Their Bioactivities, Journal of Agricultural and Food Chemistry 60 (2012) 5013-5022.

[8] XX Chen, HL Feng, YM Ding, WM Chai, ZH Xiang, Y Shi, QX Chen, Structure characterization of proanthocyanidins from Caryota ochlandra Hance and their bioactivities, Food Chemistry 155 (2014) 1-8.

[9] GJ Tanner, KT Francki, S Abrahams, JM Watson, PJ Larkin, AR Ashton, Proanthocyanidin biosynthesis in plants - Purification of legume leucoanthocyanidin reductase and molecular cloning of its cDNA, Journal of Biological Chemistry 278 (2003) 31647-31656.

[10] C Santos-Buelga, A Scalbert, Proanthocyanidins and tannin-like compounds - nature, occurrence, dietary intake and effects on nutrition and health, Journal of the Science of Food and Agriculture 80 (2000) 1094-1117.

[11] JA Kennedy, AW Taylor, Analysis of proanthocyanidins by high-performance gel permeation chromatography, Journal of Chromatography A 995 (2003) 99-107.

[12] WM Chai, CM Chen, YS Gao, HL Feng, YM Ding, Y Shi, HT Zhou, QX Chen, Structural Analysis of Proanthocyanidins Isolated from Fruit Stone of Chinese Hawthorn with Potent Antityrosinase and Antioxidant Activity, Journal of Agricultural and Food Chemistry 62 (2014) 123-129.

[13] TL Eberhardt, RA Young, CONIFER SEED CONE PROANTHOCYANIDIN POLYMERS CHARACTERIZATION BY C-13 NMR-SPECTROSCOPY AND DETERMINATION OF ANTIFUNGAL ACTIVITIES, Journal of Agricultural and Food Chemistry 42 (1994) 1704-1708.

[14] XX Chen, Y Shi, WM Chai, HL Feng, JX Zhuang, QX Chen, Condensed Tannins from Ficus virens as Tyrosinase Inhibitors: Structure, Inhibitory Activity and Molecular Mechanism, Plos One 9 (2014).

[15] HA Bawadi, RR Bansode, A Trappey, RE Truax, JN Losso, Inhibition of Caco-2 colon, MCF-7 and Hs578T breast, and DU 145 prostatic cancer cell proliferation by water-soluble black bean condensed tannins, Cancer Letters 218 (2005) 153-162.

[16] EP Lansky, HM Paavilainen, AD Pawlus, RA Newman, Ficus spp. (fig): Ethnobotany and potential as anticancer and anti-inflammatory agents, Journal of Ethnopharmacology 119 (2008) 195-213.

[17] Y Zhang, YQ Peng, SG Compton, DR Yang, Premature Attraction of Pollinators to Inaccessible Figs of Ficus altissima: A Search for Ecological and Evolutionary Consequences, Plos One 9 (2014).

[18] YQ Peng, SG Compton, DR Yang, The reproductive success of Ficus altissima and its pollinator in a strongly seasonal environment: Xishuangbanna, Southwestern China, Plant Ecology 209 (2010) 227-236.

[19] YT Wang, J Gong, LY Zhang, Development of polymorphic microsatellite loci for Eupristina altissima, the pollinating wasp of Ficus altissima (Moraceae), Conservation Genetics Resources 6 (2014) 625-627.

[20] YP Ma, YF Kong, YW Cao, YS Shi, Development and characterization of polymorphic microsatellite loci in Ficus altissima, Conservation Genetics Resources 7 (2015) 235-237.

[21] MH Omar, W Mullen, A Crozier, Identification of Proanthocyanidin Dimers and Trimers, Flavone C-Glycosides, and Antioxidants in Ficus deltoidea, a Malaysian Herbal Tea, Journal of Agricultural and Food Chemistry 59 (2011) 1363-1369.

[22] A Dey, PS De, Influence of Condensed Tannins from Ficus bengalensis Leaves on Feed Utilization, Milk Production and Antioxidant Status of Crossbred Cows, Asian-Australasian Journal of 
Animal Sciences 27 (2014) 342-348.

[23] A Dey, N Dutta, K Sharma, AK Patranaik, Response of dairy cows to dietary supplementation of condensed tannins through Ficus infectoria leaves, Indian Journal of Animal Sciences 79 (2009) 58-62.

[24] YQ Peng, JB Zhao, RD Harrison, DR Yang, Ecology of parasite Sycophilomorpha sp. on Ficus altissima and its effect on the fig-fig wasp mutualism, Parasitology 137 (2010) 1913-1919.

[25] XX Chen, XB Wu, WM Chai, HL Feng, Y Shi, HT Zhou, QX Chen, Optimization of extraction of phenolics from leaves of Ficus virens, Journal of Zhejiang University-Science B 14 (2013) 903-915.

[26] TH Terrill, AM Rowan, GB Douglas, TN Barry, DETERMINATION OF EXTRACTABLE AND BOUND CONDENSED TANNIN CONCENTRATIONS IN FORAGE PLANTS, PROTEIN-CONCENTRATE MEALS AND CEREAL-GRAINS, Journal of the Science of Food and Agriculture 58 (1992) 321-329.

[27] R Re, N Pellegrini, A Proteggente, A Pannala, M Yang, C Rice-Evans, Antioxidant activity applying an improved ABTS radical cation decolorization assay, Free Radical Biology and Medicine 26 (1999) 1231-1237.

[28] SY Kim, JY Je, SK Kim, Purification and characterization of antioxidant peptide from hoki (Johnius belengerii) frame protein by gastrointestinal digestion, Journal of Nutritional Biochemistry 18 (2007) 31-38.

[29] XY Fu, DM Tan, ZH Hou, ZL Hu, GZ Liu, Y Ouyang, F Liu, MicroRNA expression profiles of LO2 cells expressing the wild-type and mutant HBx gene, Molecular Medicine Reports 7 (2013) 633-641.

[30] PH Luo, QJ He, XG He, YZ Hu, W Lu, YY Cheng, B Yang, Potent antitumor activity of 10-methoxy-9-nitrocamptothecin, Molecular Cancer Therapeutics 5 (2006) 962-968.

[31] ZC Li, LH Chen, XJ Yu, YH Hu, KK Song, XW Zhou, QX Chen, Inhibition Kinetics of Chlorobenzaldehyde Thiosemicarbazones on Mushroom Tyrosinase, Journal of Agricultural and Food Chemistry 58 (2010) 12537-12540.

[32] ESS Abdel-Hameed, Total phenolic contents and free radical scavenging activity of certain Egyptian Ficus species leaf samples, Food Chemistry 114 (2009) 1271-1277.

[33] I Gulcin, Antioxidant properties of resveratrol: A structure-activity insight, Innovative Food Science \& Emerging Technologies 11 (2010) 210-218.

[34] DJ Huang, BX Ou, RL Prior, The chemistry behind antioxidant capacity assays, Journal of Agricultural and Food Chemistry 53 (2005) 1841-1856.

[35] G Kapravelou, R Martinez, AM Andrade, CL Chaves, M Lopez-Jurado, P Aranda, F Arrebola, FJ Canizares, M Galisteo, JM Porres, Improvement of the antioxidant and hypolipidaemic effects of cowpea flours (Vigna unguiculata) by fermentation: results of in vitro and in vivo experiments, Journal of the Science of Food and Agriculture 95 (2015) 1207-1216.

[36] Rockenbach, II, LV Gonzaga, VM Rizelio, A Goncalves, MI Genovese, R Fett, Phenolic compounds and antioxidant activity of seed and skin extracts of red grape (Vitis vinifera and Vitis labrusca) pomace from Brazilian winemaking, Food Research International 44 (2011) 897-901.

[37] M Viuda-Martos, Y Ruiz-Navajas, J Fernandez-Lopez, E Sendra, E Sayas-Barbera, JA Perez-Alvarez, Antioxidant properties of pomegranate (Punica granatum L.) bagasses obtained as co-product in the juice extraction, Food Research International 44 (2011) 1217-1223.

[38] YT Zhang, Q Li, H Xing, XF Lu, LS Zhao, KK Qu, KS Bi, Evaluation of antioxidant activity of ten compounds in different tea samples by means of an on-line HPLC-DPPH assay, Food Research 
International 53 (2013) 847-856.

[39] IFF Benzie, JJ Strain, The ferric reducing ability of plasma (FRAP) as a measure of "antioxidant power": The FRAP assay, Analytical Biochemistry 239 (1996) 70-76.

[40] JK da Silva, CBB Cazarin, TC Colomeu, AG Batista, LMM Meletti, JAR Paschoal, S Bogusz, MF Furlan, FGR Reyes, F Augusto, MR Marostica, RD Zollner, Antioxidant activity of aqueous extract of passion fruit (Passiflora edulis) leaves: In vitro and in vivo study, Food Research International 53 (2013) 882-890.

[41] MM Schmidt, RC Prestes, EH Kubota, G Scapin, MA Mazutti, Evaluation of antioxidant activity of extracts of banana inflorescences (Musa cavendishii), Cyta-Journal of Food 13 (2015) 498-505.

[42] JA Kennedy, GP Jones, Analysis of proanthocyanidin cleavage products following acid-catalysis in the presence of excess phloroglucinol, Journal of Agricultural and Food Chemistry 49 (2001) 1740-1746.

[43] WM Chai, MK Wei, R Wang, RG Deng, ZR Zou, YY Peng, Avocado Proanthocyanidins as a Source of Tyrosinase Inhibitors: Structure Characterization, Inhibitory Activity, and Mechanism, Journal of Agricultural and Food Chemistry 63 (2015) 7381-7387.

[44] P Cos, T De Bruyne, N Hermans, S Apers, D Vanden Berghe, AJ Vlietinck, Proanthocyanidins in health care: Current and new trends, Current Medicinal Chemistry 11 (2004) 1345-1359.

[45] BN Singh, BR Singh, RL Singh, D Prakash, R Dhakarey, G Upadhyay, HB Singh, Oxidative DNA damage protective activity, antioxidant and anti-quorum sensing potentials of Moringa oleifera, Food and Chemical Toxicology 47 (2009) 1109-1116.

[46] JC Lee, HR Kim, J Kim, YS Jang, Antioxidant property of an ethanol extract of the stem of Opuntia ficus-indica var. saboten, Journal of Agricultural and Food Chemistry 50 (2002) 6490-6496.

[47] B Cheng, YC Zheng, XR Guo, Y Wang, CY Liu, Hepatitis B viral X protein alters the biological features and expressions of DNA repair enzymes in LO2 cells, Liver International 30 (2010) 319-326.

[48] Y Kim, Y Choi, H Ham, HS Jeong, J Lee, Protective effects of oligomeric and polymeric procyanidin fractions from defatted grape seeds on tert-butyl hydroperoxide-induced oxidative damage in HepG2 cells, Food Chemistry 137 (2013) 136-141.

[49] YH Jo, GU Seo, HG Yuk, SC Lee, Antioxidant and tyrosinase inhibitory activities of methanol extracts from Magnolia denudata and Magnolia denudata var. purpurascens flowers, Food Research International 47 (2012) 197-200.

[50] CY Wang, CC Ng, HT Lin, YT Shyu, Free radical-scavenging and tyrosinase-inhibiting activities of extracts from sorghum distillery residue, Journal of Bioscience and Bioengineering 111 (2011) 554-556.

[51] D Kim, J Park, J Kim, C Han, J Yoon, N Kim, J Seo, C Lee, Flavonoids as mushroom tyrosinase inhibitors: A fluorescence quenching study, Journal of Agricultural and Food Chemistry 54 (2006) 935-941. 


\section{Legends of figures}

Fig. 1 Chemical structures of flavan-3-ol monomer units: R1, R2=H, (epi) afzelechin; $\mathrm{R} 1=\mathrm{OH}, \mathrm{R} 2=\mathrm{H}$, (epi) catechin; R1, R2=OH, (epi) gallocatechin.

Fig. 2 Antioxidant activity of crude extracts and condensed tannins from leaves of Ficus altissima. (A) DPPH radical scavenging activity. (B) ABTS radical scavenging activity, and (C) ferric-reducing antioxidant power. Means in one group not sharing the same letters differ significantly $(p<0.05)$.

Fig. 3 Reversed-phase HPLC-ESI-MS chromatogram of condensed tannins from leaves of Ficus altissima. Terminal units: C, catechin, EC, epicatechin. Extender unit: EC-thio: epicatechin benzylthioether; (E)G-thio: (epi)gallocatechin benzylthioether; C-thio: catechin benzylthioether; (E)A-thio: (epi)afzelechin benzylthioether; BM, benzyl mercaptan.

Fig. 4 MALDI-TOF positive-ion mode mass spectra of condensed tannins from Ficus altissima leaves. (A) Reflectron mode; (B) linear mode.

Fig. 5 Protective effect of condensed tannins from Ficus altissima leaves against pLV plasmid DNA damage caused by hydroxyl radicals. Lane 1: plasmid DNA only; Lane 2: plasmid DNA $+\mathrm{FeSO}_{4}+\mathrm{H}_{2} \mathrm{O}_{2}$; Lane 3-6: plasmid DNA $+\mathrm{FeSO}_{4}+\mathrm{H}_{2} \mathrm{O}_{2}+$ condensed tannins $(6.25,12.5,25$, and $50 \mu \mathrm{g} / \mathrm{mL})$.

Fig. 6 (A) Inhibitory effect of condensed tannins from Ficus altissima leaves on monophenolase activity of mushroom tyrosinase. (a) Progress curves for the oxidation 
of ${ }_{L}$-Tyr by the enzyme. The concentrations of the condensed tannins for curves $1-6$ were $0,40,120,200,400$, and $600 \mu \mathrm{g} / \mathrm{mL}$, respectively. (b) Effect of condensed tannins on the steady-state rates of monophenolase. (c) Effect of condensed tannins on the lag time of mushroom tyrosinase. (B) Inhibitory effect and mechanism of condensed tannins from Ficus altissima leaves on diphenolase activity of mushroom tyrosinase. (C) Inhibitory type and inhibition constants of condensed tannins from Ficus altissima leaves on diphenolase activity of mushroom tyrosinase. (D) Fluorescence emission spectra of tyrosinase solution with various concentrations of condensed tannins from Ficus altissima leaves. The concentrations of condensed tannins for curve $0-3$ were $0,5,10$, and $20 \mu \mathrm{g} / \mathrm{mL}$, respectively. Curve A was attributed to the fluorescence emission spectrum of condensed tannins at the concentration of $200 \mu \mathrm{g} / \mathrm{mL}$. 


\section{Table 1}

Protective effect of condensed tannins from Ficus altissima against $t$-BHP in LO2 cells

\begin{tabular}{|c|c|c|c|c|}
\hline $\begin{array}{c}\text { Condensed } \\
\text { tannins }(\mu \mathrm{g} / \mathrm{mL})\end{array}$ & 12.5 & 25 & 50 & 100 \\
\hline Viability $1^{\mathrm{a}}(\%)$ & $115.4 \pm 3.2$ & $125.2 \pm 2.0^{*}$ & $128.9 \pm 4.6^{*}$ & $116.4 \pm 7.5$ \\
\hline Viability $2^{\mathrm{b}}(\%)$ & $134.6 \pm 14.1$ & $161.8 \pm 8.3^{*}$ & $167.9 \pm 3.1^{*}$ & $181.4 \pm 6.4^{*}$ \\
\hline Viability $3^{\mathrm{c}}(\%)$ & $116.9 \pm 15.7$ & $129.2 \pm 4.7^{*}$ & $130.4 \pm 6.2$ & $156.1 \pm 7.3^{*}$ \\
\hline
\end{tabular}

${ }^{\mathrm{a}}$ Viability 1: Viability of LO2 cells when treated with condensed tannins only. ${ }^{\mathrm{b}}$ Viability 2 :

Viability of LO2 cells when simultaneously treated with condensed tannins and t-BHP. ${ }^{\mathrm{c}}$ Viability

3: Amount of viability 2 divided by viability $1 .{ }^{*}$ Statistical significance $(p<0.05)$. 


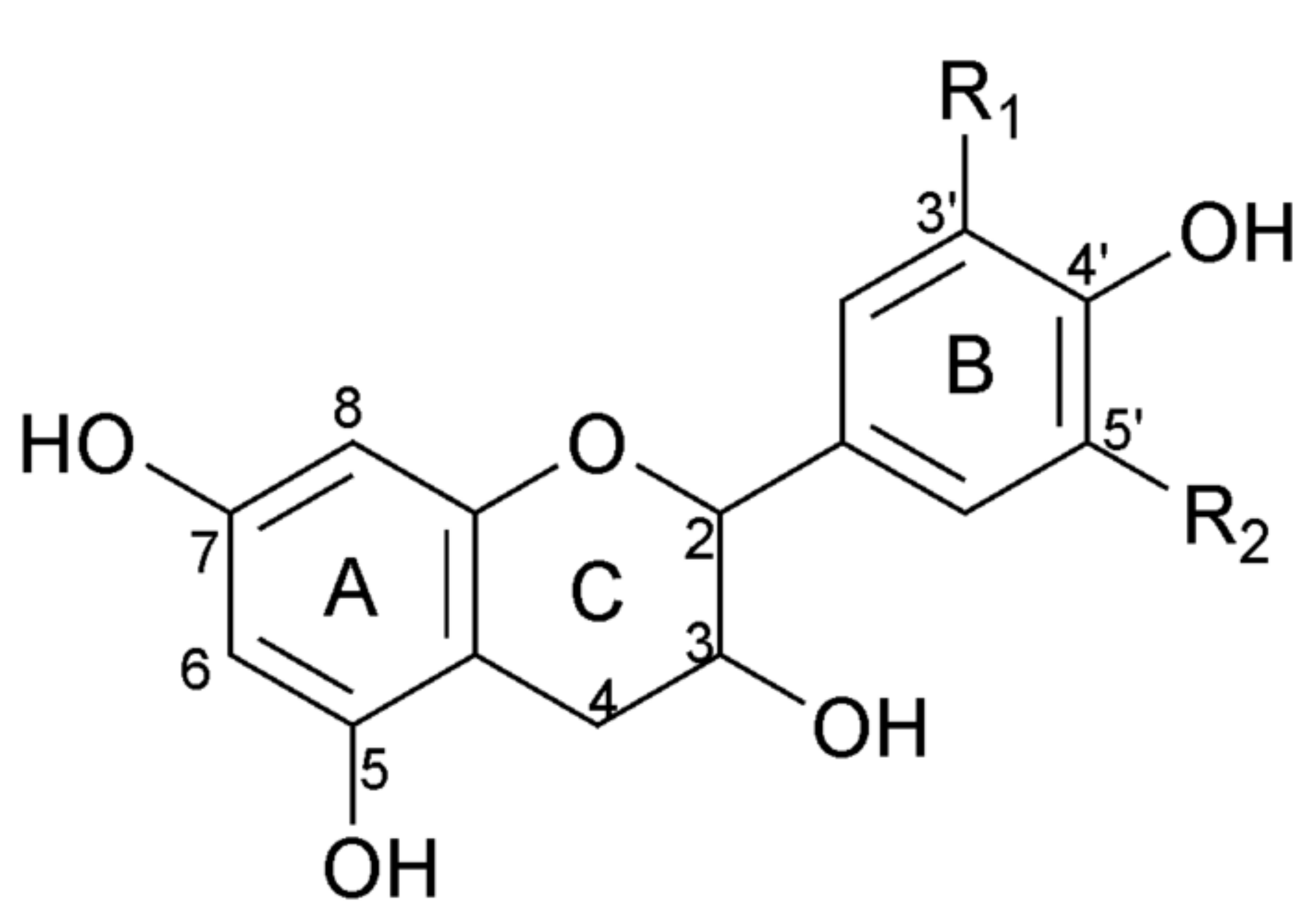

(1) 
Figure(s)
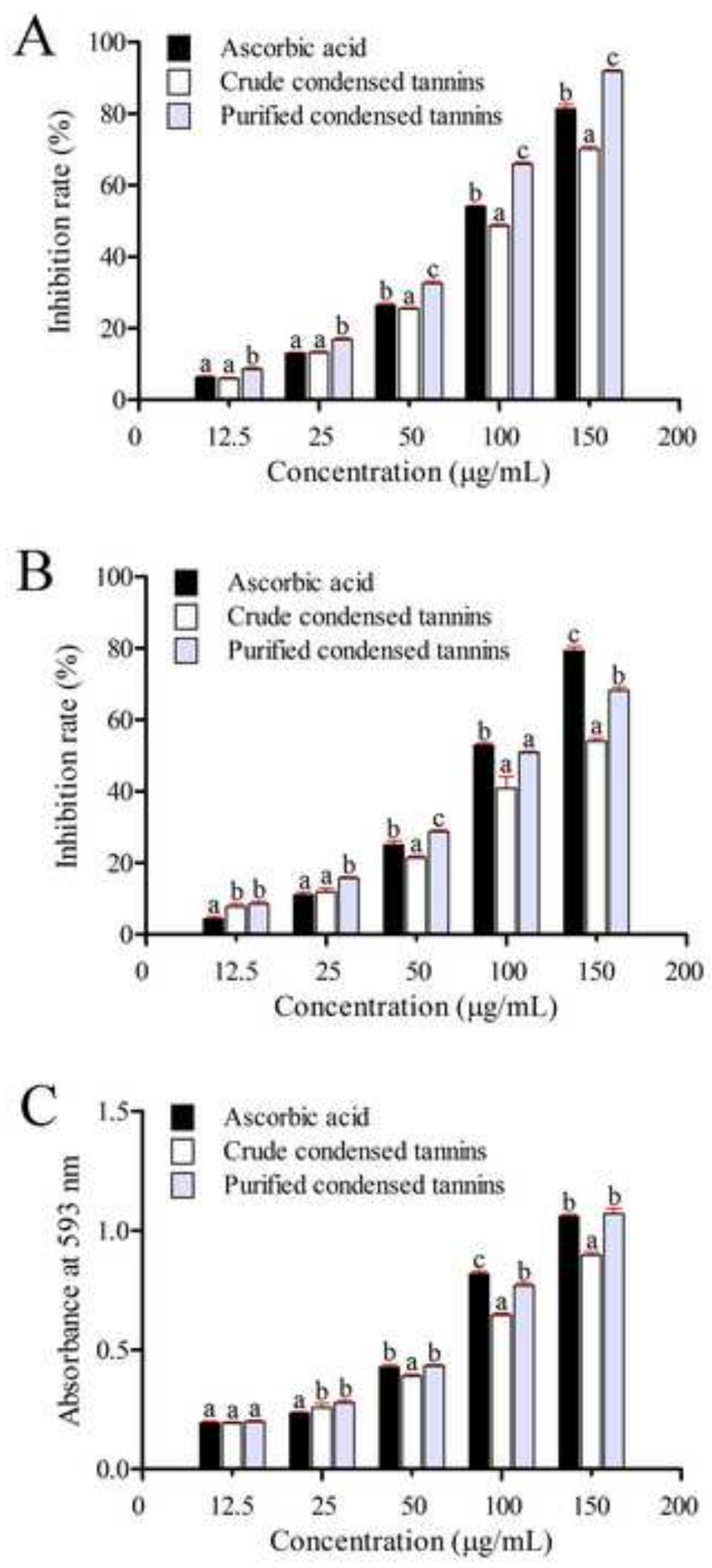


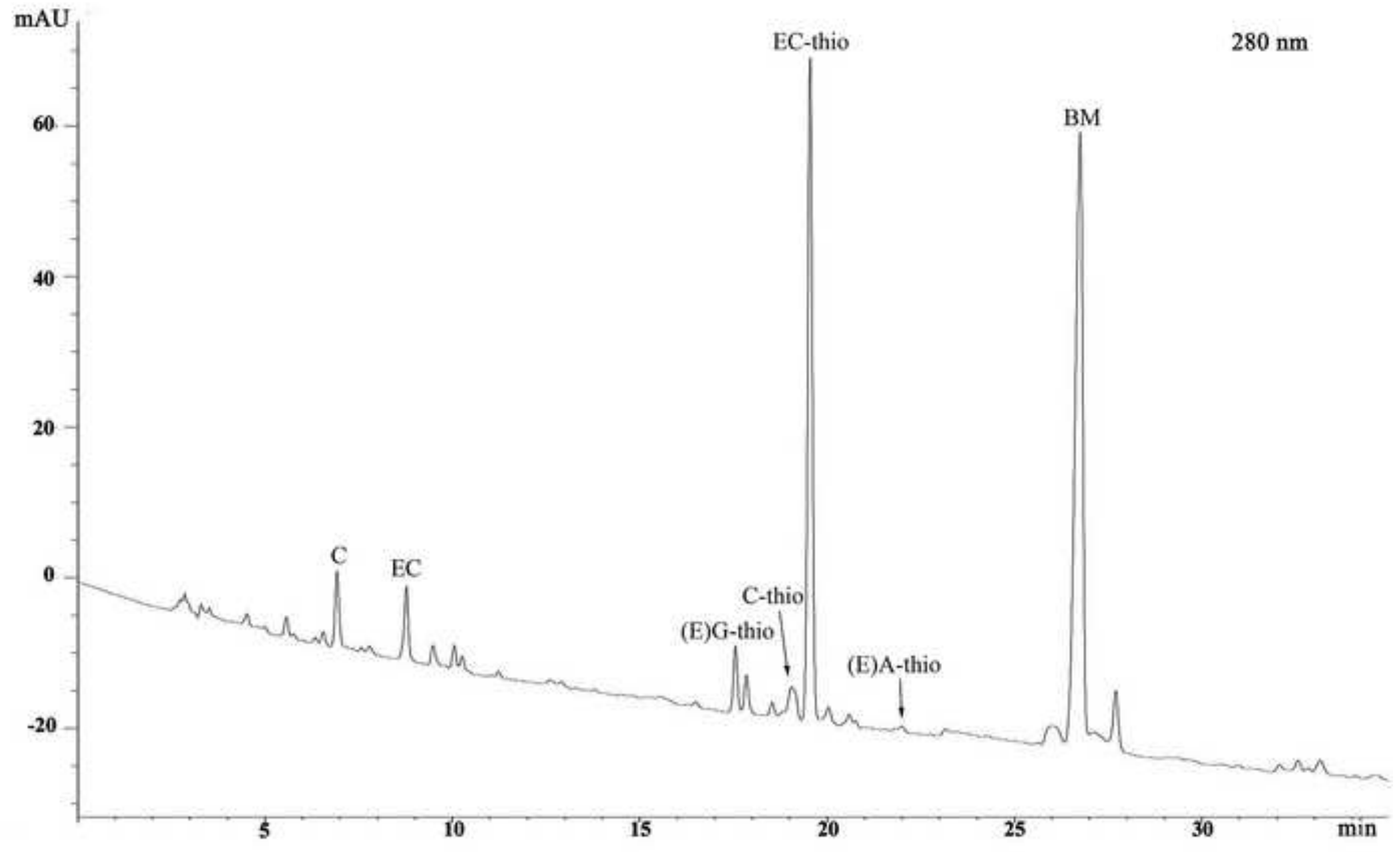


Figure(s)
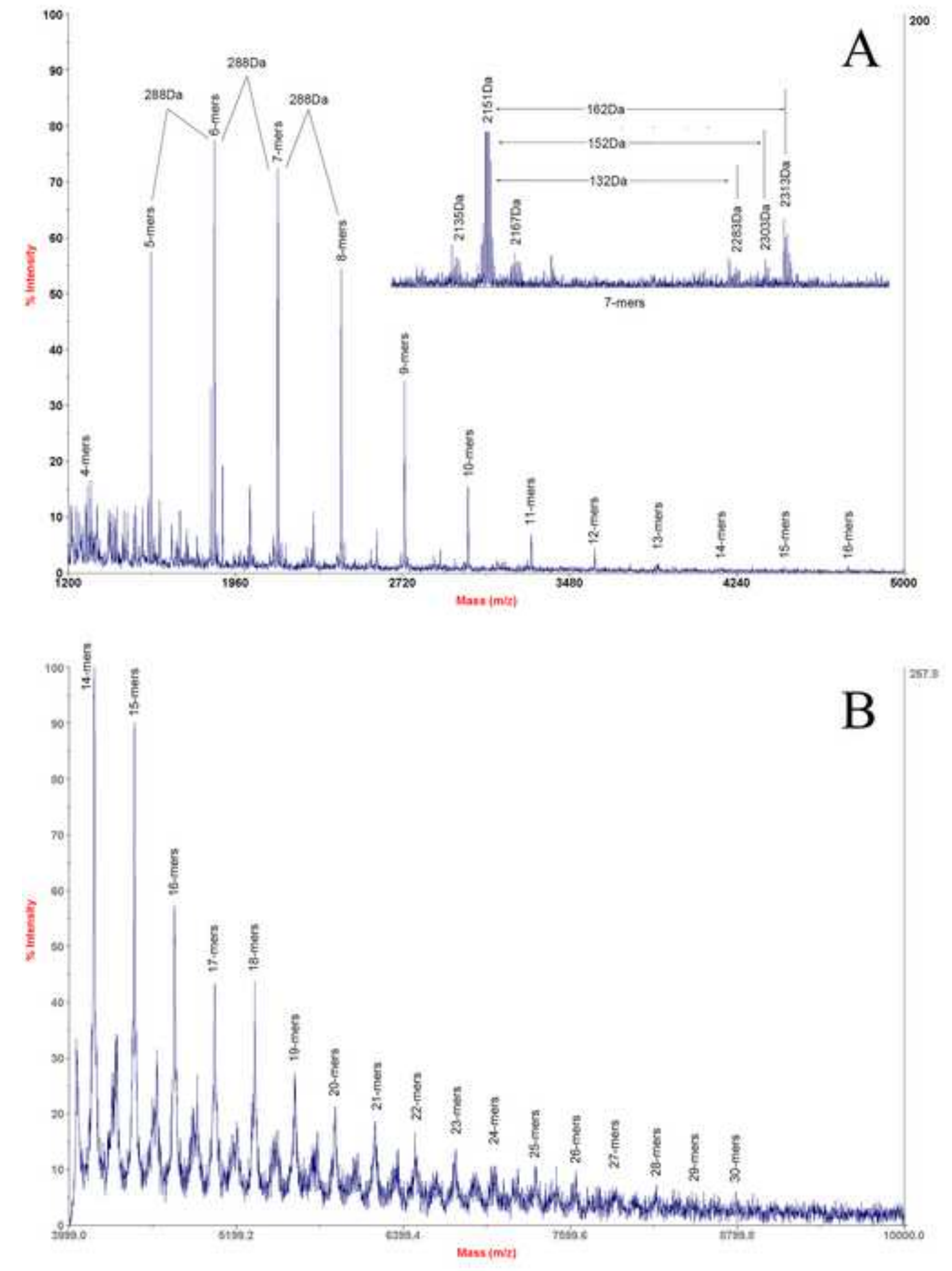


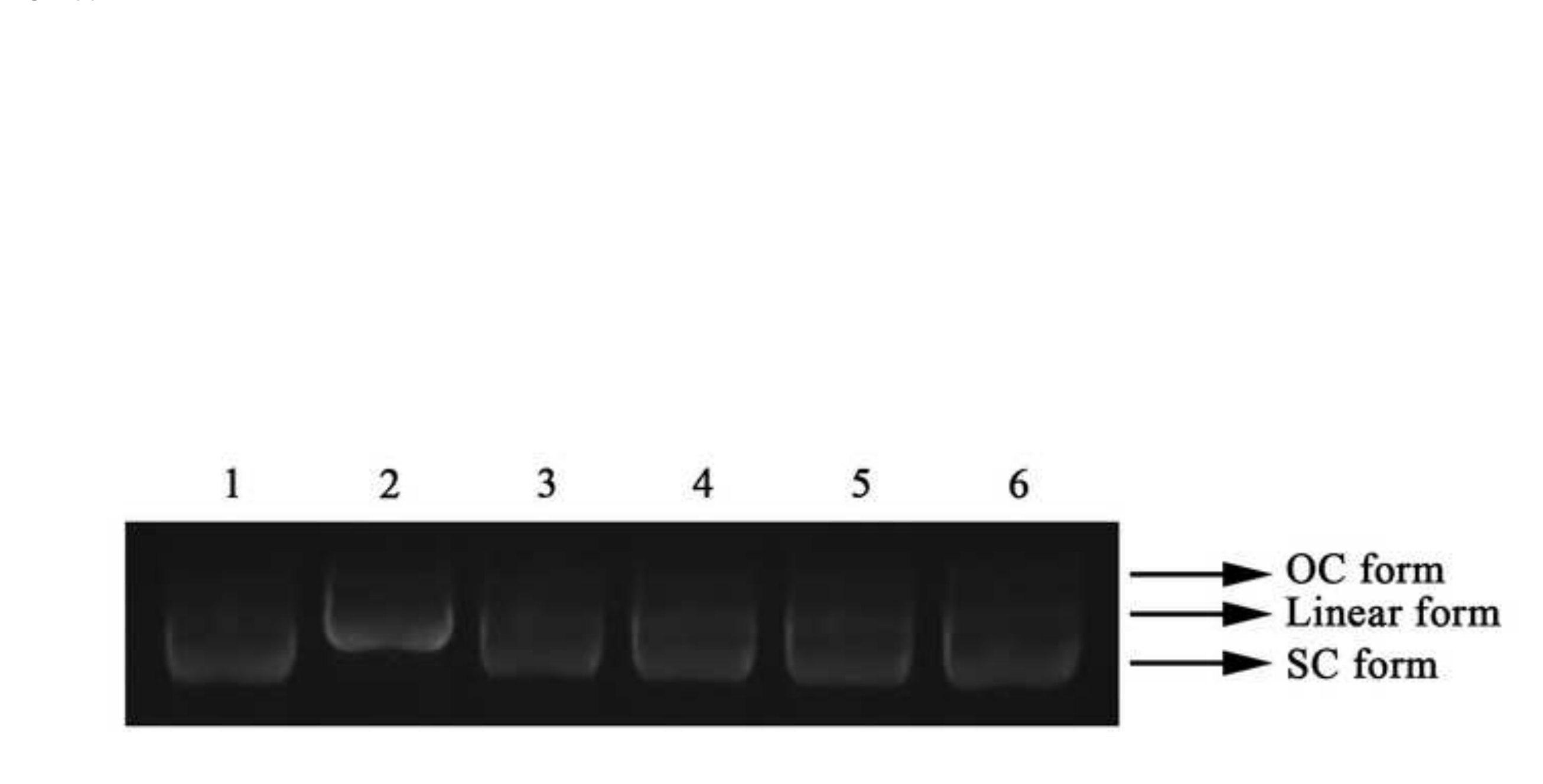




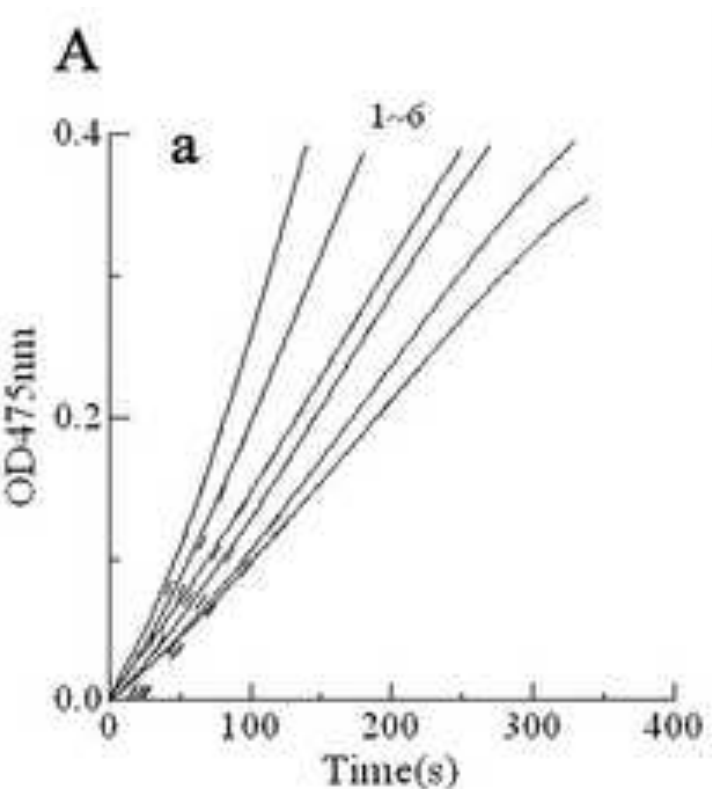

B

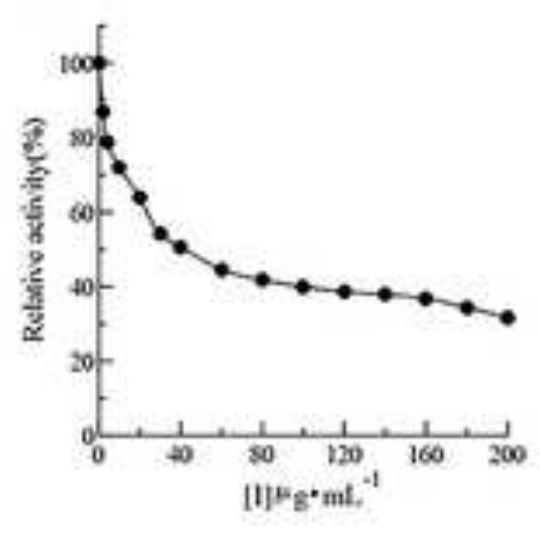

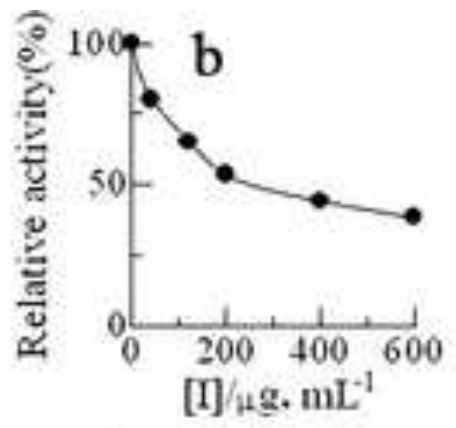
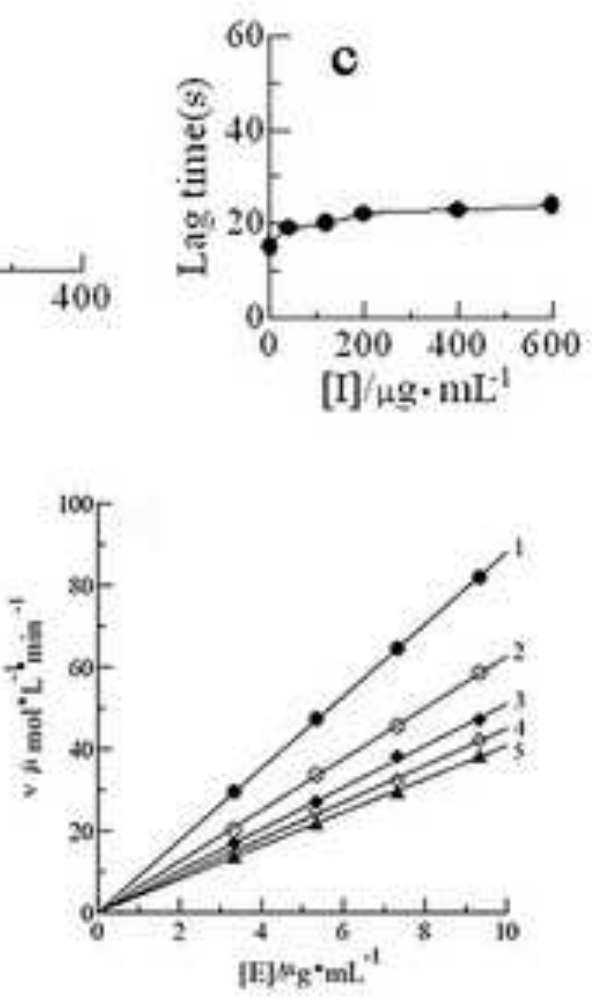

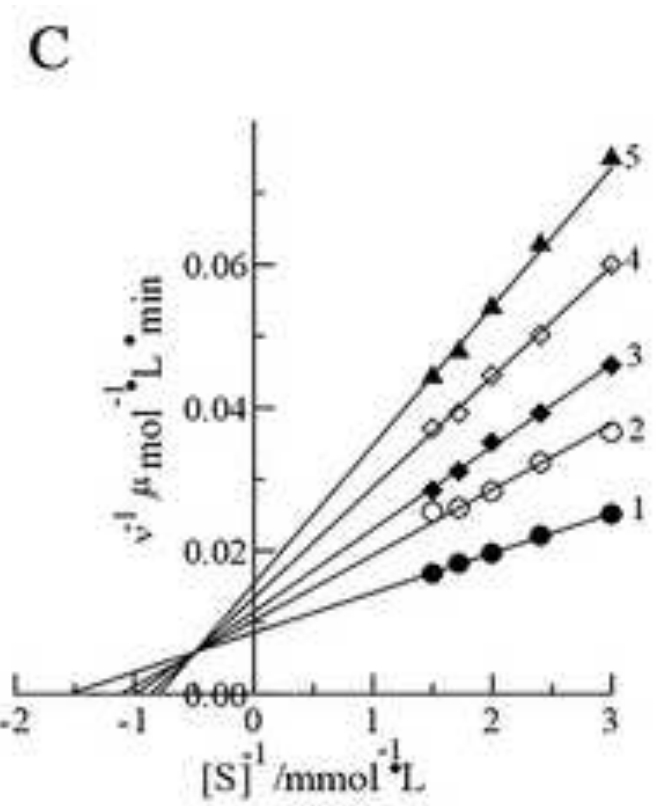

D

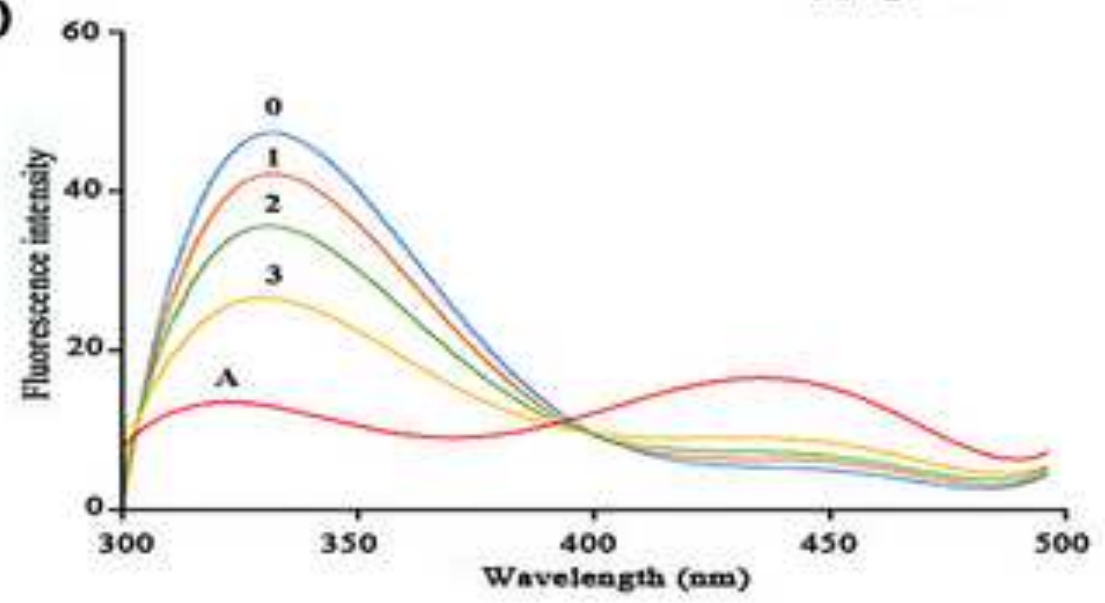

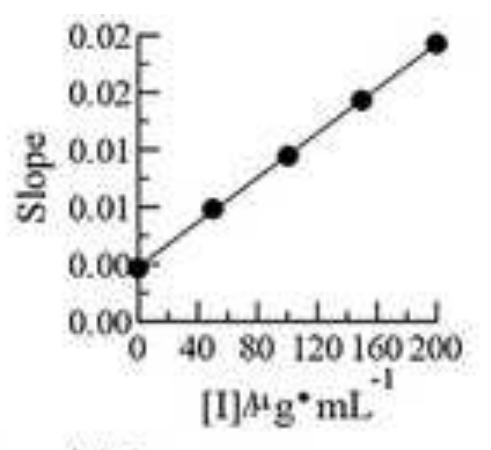

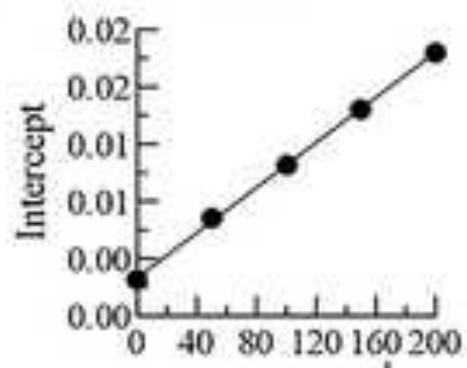

[I] $\mu^{\mu} \mathrm{g}^{*} \mathrm{~mL}^{-1}$ 


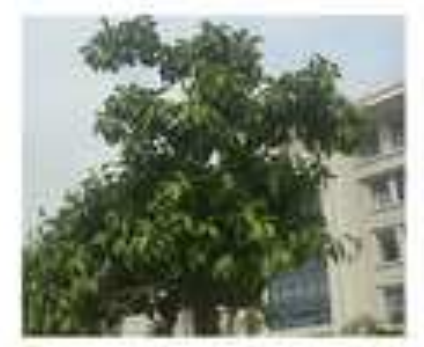

Ficus altissima leaves

Lyophilization

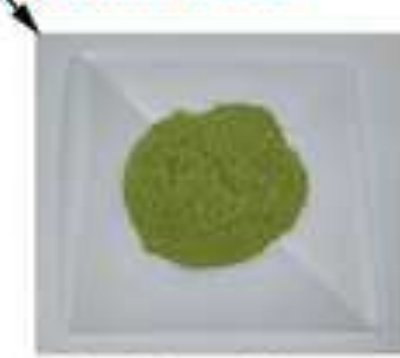

Crude extracts Extraction

Chromatography

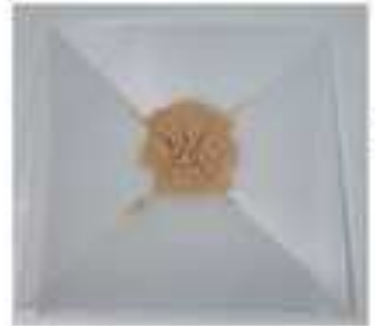

Structural characterization

Powders of leaves

Condensed tannins

Antioxidant property

Antityrosinase activity 